\title{
Federalismo, dinâmica eleitoral e políticas públicas no Brasil: uma tipologia e algumas hipóteses
}

ANDRÉ BORGES:

\section{Resumo}

O presente trabalho propõe um modelo tipológico capaz de fundamentar o entendimento da conexão entre políticas públicas e dinâmica eleitoral em uma democracia federal onde o poder de formular e implementar políticas públicas é relativamente descentralizado. De modo mais geral, esta tipologia de políticas públicas pretende avançar além das dicotomias tradicionais da ciência política - clientelismo vs. universalismo / partidos catch-all vs. partidos programáticos - oferecendo uma nova perspectiva analítica, de corte não dualista. A tipologia classifica as políticas públicas a partir de duas dimensões: os critérios de alocação de recursos (políticopartidários ou universalistas) e a natureza dos bens e serviços produzidos (privados ou públicos). A partir do cruzamento das duas dimensões, o trabalho define quatro tipos de estratégias de implementação de políticas públicas: clientelismo, política distributiva, focalização e universalismo. Também são definidas algumas hipóteses capazes de explicar as escolhas de política pública realizadas pelos governos subnacionais. O trabalho leva em conta três ordens de fatores explicativos: competição política horizontal (entre partidos políticos), competição vertical (entre esferas de governo) e contexto socioeconômico e demográfico.

Palavras-chave: Políticas públicas. Clientelismo. Competição eleitoral. Federalimo. Governo estadual.

* Professor Adjunto do Instituto de Ciência Política da Universidade de Brasília. 


\section{Introdução}

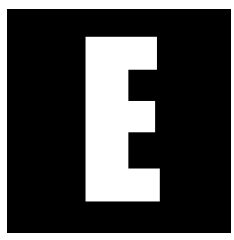

$\mathrm{m}$ democracias federais onde o poder de formular e implementar políticas públicas é significativamente descentralizado entre as esferas de governo, as autoridades subnacionais terão, com frequência, tanto incentivos quanto instrumentos para influenciar os resultados das eleições regionais e nacionais e até mesmo construir organizações políticas relativamente independentes dos partidos nacionais. Especialmente naqueles sistemas políticos onde as instituições partidárias são descentralizadas, a capacidade das elites estaduais e locais de distribuir cargos e verbas públicas entre eleitores e membros dos partidos deverá ser extremamente importante na estruturação dos processos partidários e eleitorais em todos os níveis.

A democracia brasileira é precisamente um exemplo de sistema político onde as instituições e interesses subnacionais desempenham papel substancial na dinâmica eleitoral e de formulação de políticas públicas. A Constituição de 1988 introduziu uma variante "robusta" de federalismo, em que os governos locais e, especialmente, estaduais, ganharam a capacidade de implementar um amplo leque de políticas sociais e econômicas, e ainda garantiram, sob diversas formas, a representação dos interesses subnacionais na arena política nacional (AMES, 1987; HAGOPIAN, 1996; MAINWARING, 1997). Para a maioria dos analistas políticos, o "novo federalismo" permitiu a emergência dos governadores dos estados como atores políticos poderosos, ainda que existam discordâncias sobre o grau em que as elites estaduais seriam capazes de exercer influência direta sobre o processo decisório nacional (ABRUCIO, 1998; ARRETCHE, 2000; MAINWARING, 1999; SOUZA, 1997).

Um outro aspecto importante do funcionamento de democracias federais, este bem menos lembrado nas análises do caso brasileiro, diz 
respeito aos processos de competição vertical entre esferas de governo distintas na produção de políticas públicas. Em sistemas políticos federativos onde a autoridade sobre a formulação e implementação de políticas públicas é descentralizada, o governo central e os governos subnacionais competem por um mesmo "pool" de eleitores ao ofertar serviços similares em um dado território. Isto é, ao buscar o apoio do eleitorado por meio de políticas de gasto social, os governos estaduais ou locais competem com políticas similares ofertadas pelo governo federal (MIGUÉ, 1997). Os impactos da competição vertical no federalismo brasileiro ainda são pouco conhecidos e estudados, mas já há evidências de que a expansão das políticas sociais federais de transferência de renda nos últimos anos vem contribuindo para minar o controle antes exercido pelas máquinas políticas estaduais sobre a arena eleitoral (BORGES, 2007).

Via de regra, as pesquisas sobre a conexão entre voto e políticas públicas vem se concentrando na esfera nacional e no poder Legislativo. Estes estudos procuram estabelecer uma relação entre as emendas ao orçamento da União e o desempenho eleitoral e comportamento legislativo dos parlamentares (AMES, 2001; PEREIRA; RENNÓ, 2001). Na medida em que as pesquisas vêm enfocando majoritariamente o Congresso, ainda sabemos pouco sobre a conexão eleitoral das políticas públicas na esfera subnacional e menos ainda sobre os processos de competição vertical entre os governos central e subnacionais. Também há uma carência de estudos sobre o papel do Poder Executivo - instituição central no presidencialismo brasileiro - no processo decisório e na conexão eleitoral das políticas públicas.

Considerando as lacunas da literatura - mas sem a pretensão de dar conta destas - o presente trabalho propõe um modelo tipológico capaz de auxiliar o nosso entendimento da conexão entre políticas sociais e resultados eleitorais em uma democracia federal onde o poder de formular e implementar políticas públicas é relativamente descentralizado. 
De modo mais geral, esta tipologia de políticas públicas pretende avançar além das dicotomias tradicionais da ciência política - clientelismo vs. universalismo / partidos catch-all vs. partidos programáticos - oferecendo uma nova perspectiva analítica, de corte não dualista. As pesquisas sobre políticas públicas produzidas no Brasil se utilizam, muitas vezes, de termos como "clientelismo", "assistencialismo" e "patrimonialismo" de forma imprecisa, sem um maior rigor teórico e metodológico, e com fortes vieses normativos. Não há a preocupação de se pensar analiticamente as distinções/semelhanças entre programas governamentais, nem como políticas públicas distintas tendem a impactar/sofrer influências distintas nos/dos processos eleitorais e partidários.

A tipologia desenvolvida neste trabalho classifica as políticas públicas a partir de duas dimensões: os critérios de alocação de recursos (políticopartidários ou universalistas) e a natureza dos bens e serviços produzidos (privados ou públicos). A partir do cruzamento das duas dimensões, são definidos quatro tipos de estratégias de implementação de políticas públicas: clientelismo, política distributiva, focalização e universalismo. A partir desta classificação, são definidas algumas hipóteses para dar conta das escolhas de política pública realizadas pelos governos subnacionais. São consideradas três ordens de fatores explicativos: competição política horizontal (entre partidos políticos), competição vertical (entre esferas de governo) e contexto socioeconômico e demográfico.

\section{Clientelismo e política distributiva: uma revisão conceitual}

Uma primeira reflexão conceitual a ser desenvolvida neste trabalho trata dos conceitos de clientelismo e política distributiva. Embora estes conceitos estejam relacionados entre si, existem distinções e nuances importantes que nem sempre são observadas pela literatura. Na definição 
clássica da literatura da antropologia política, o clientelismo é entendido como uma relação de poder assimétrica, usualmente envolvendo algum tipo de troca ou barganha, entre patrons e clientes ${ }^{1}$. Via de regra, os patrons detêm o controle sobre o acesso a determinados bens ou serviços desejados pela clientela, o que lhes permite exercer poder sobre os clientes (GELLNER, 1977; WATERBURY, 1977). Nas democracias modernas, a relação clientelista tradicional, presente em sociedades agrárias onde a posse da terra é fundamental para a distribuição de poder e status, cede espaço às clientelas políticas associadas aos partidos, embora os padrões e normas do clientelismo tradicional se mantenham (DINIZ, 1982).

A utilização do conceito de clientelismo pela ciência política sempre se mostrou problemática, entre outras razões pelo fato de se tratar de um termo desenvolvido na antropologia a partir de métodos e perspectivas estranhas à análise política ${ }^{2}$. Um outro aspecto não menos importante é que a relação clientelista tende a se verificar mais comumente em uma situação em que as políticas públicas sendo ofertadas se aproximam da definição de bens privados, ou seja, bens divisíveis e excludentes que geram benefícios estritamente individuais. Um exemplo seria a distribuição de cargos públicos entre eleitores e simpatizantes do partido, pois esta política produziria benefícios tão somente para os agraciados com uma nomeação. O motivo pelo qual o clientelismo tende a estar associado a ideia de bens privados é simplesmente pelo fato de que este tipo de política pública facilita a exclusão. Isto é, do ponto de vista do governo é mais

\footnotetext{
1 O termo "patron" não encontra equivalente apropriado no Brasil, dizendo respeito tanto ao "coronel" característico de formações agrárias quanto ao chefe de máquinas políticas urbanas. 2 O problema mais evidente diz respeito ao nível de análise utilizado por cientistas políticos e antropólogos. Os estudos antropológicos sobre clientelismo enfocam, via de regra, o nível micro das relações entre indivíduos, enquanto a ciência política tende a trabalhar no nível macro, não raro com dados quantitativos agregados. Em decorrência, nos estudos políticos o clientelismo é muitas vezes inferido por meio de uma passagem metodologicamente problemática do nível macro dos dados eleitorais e das políticas públicas para o nível micro das relações individuais.
} 
fácil assegurar a exclusão dos eleitores oposicionistas do acesso a uma cesta básica ou a um cargo político, do que excluir estes mesmos eleitores dos benefícios propiciados por uma escola ou um hospital construído numa dada localidade. Isto porque, em tese, enquanto um bem privado como uma cesta básica produz, no limite, benefícios estritamente individuais, bens e serviços que se aproximam da definição de bens públicos (i.e. que geram externalidades positivas) produzem benefícios coletivos (DIAZ-CAYEROS et al., 2003)

Aqui vale a pena relembrar a clássica distinção entre bens públicos e privados: enquanto bens privados puros são rivais e excludentes, bens públicos são não-rivais e não-excludentes. Por exemplo, políticas de controle da poluição produzem um bem público que é uma atmosfera mais limpa. Em princípio, ninguém pode ser excluído do consumo deste bem (nãoexclusão). Além disso, o fato de um indivíduo A usufruir de uma atmosfera mais limpa não reduz (em tese) a quantidade deste benefício disponível para os demais (não-rivalidade). No caso dos bens privados, isto não se verifica, pois se o indivíduo A comprar a última maçã disponível no supermercado, os demais consumidores não mais poderão usufruir deste bem.

É preciso notar que bens públicos e bens privados representam situações extremas, tipos-ideais que raramente correspondem ao mundo empírico. A maioria das políticas públicas não se encaixa perfeitamente em nenhuma das duas definições. A espacialização de políticas em áreas como saúde, educação, saneamento, etc., envolve a oferta dos chamados bens públicos locais. Trata-se de bens não divisíveis que geram externalidades positivas de âmbito local (ex. uma ponte, uma escola). Este tipo de política pública não permite a discriminação direta entre eleitores, mas por outro lado faculta ao governo focalizar os recursos em municípios específicos.

O que se quer argumentar aqui é que muitas políticas públicas que supostamente abririam espaço para o estabelecimento de relações cliente- 
listas, como, por exemplo, políticas de construção de escolas e hospitais não se enquadram muito bem na definição de bens privados e, portanto, não podem ser entendidas da forma mais adequada sob o prisma do clientelismo "puro". Isto não quer dizer que não seja possível a instrumentalização político-eleitoral destas políticas públicas, mas sim que esta instrumentalização se faz, quase sempre, por via indireta, através da focalização de recursos em determinados distritos ou municípios. Ou seja, embora nem sempre seja possível (ou desejável) ao partido do governo excluir todos os eleitores oposicionistas do município $x$ do acesso a uma escola, ainda assim é possível "premiar" os municípios onde a maioria do eleitorado votou no governo nas eleições passadas concentrando recursos nestes e ao mesmo tempo "punir" os municípios oposicionistas negando-lhes novos investimentos.

As políticas públicas que permitem este tipo de discriminação entre distritos são geralmente denominadas de políticas distributivas ou pork-barrel. $\mathrm{Na}$ literatura de estudos legislativos desenvolvida nos Estados Unidos, as políticas distributivas foram definidas como políticas que concentram benefícios em uma "constituency" geográfica específica, mas dispersam os custos por toda a população através de impostos gerais. Mesmo quando estas políticas públicas geram benefícios coletivos, como no caso da construção de escolas, estes benefícios são circunscritos a um determinado município ou região geográfica (para uma revisão desta literatura, ver LIMONGI, 1994).

É importante observar que na hipótese da utilização estratégica de políticas distributivas não está presente a ideia de uma conexão direta entre o recebimento de um dado benefício pelo eleitor e uma recompensa dada ao governo na forma de um voto de apoio, especialmente naqueles casos em que a política pública se aproxima da definição de bem público (em nível municipal). Por exemplo, quando o município governista x é "premiado" com uma escola, o fato é que há uma alta probabilidade de que tanto eleitores oposicionistas quanto governistas serão beneficiados 
e, portanto, a possibilidade de "enforcement" da barganha clientelista é, no máximo, indireta. Quanto mais heterogêneo for o eleitorado do município e/ou a clientela da política pública em questão, tanto mais arriscado será o investimento feito pelo governo, pois maior será a dificuldade de estimar, ainda que grosseiramente, a resposta do eleitor aos benefícios concedidos (DIAZ-CAYEROS et al., 2003).

\section{Bens privados, bens públicos e política subnacional no Brasil}

Como podemos aplicar estes conceitos à análise da política brasileira? Aqui tomarei como ponto de partida o trabalho comparativo de Desposatto (2001) sobre os sistemas partidários estaduais. O argumento desenvolvido nesta pesquisa é que existem diferenças significativas entre os estados no que diz respeito ao comportamento dos legisladores e à provisão de políticas públicas, e que estas diferenças por sua vez estão relacionadas a diferenças socioeconômicas, demográficas e culturais. Nos estados mais pobres, segundo Desposatto (2001) os partidos de oposição nas assembleias estaduais são mais frágeis e sujeitos à cooptação do Poder Executivo, e a capacidade de formação de agenda e profissionalização dos Legislativos são limitadas. Isto aconteceria porque a sobrevivência política dos deputados nestes locais dependeria mais fortemente da capacidade de entregar bens privados aos eleitores, obrigando-os a buscar acesso aos recursos de patronagem controlados pelo Executivo.

Em linhas gerais, a pesquisa de Desposatto se apoia em já conhecidos argumentos estruturais sobre a relação entre política clientelista e variáveis como pobreza e nível de renda. Em regiões pobres e de baixo desenvolvimento econômico social, o efeito de políticas distributivas sobre o bemestar dos eleitores deve ser maior do que em regiões de alta renda e alto desenvolvimento, entre outras razões porque nas primeiras, ceteris paribus, 
a dependência dos agentes privados em relação ao governo também deve ser maior (DIAZ-CAYEROS et al., 2003; STOKES; MEDINA, 2002). Além disso, pressupondo-se que a utilidade obtida por cada unidade monetária adicional de renda é inversamente relacionada à magnitude total da renda (utilidade marginal da renda decrescente), é de se esperar que os eleitores pobres tenham maior sensibilidade a políticas públicas que aumentam direta ou indiretamente o seu nível de renda (CALVO; MURILLO, 2004).

As características sociodemográficas dos distritos eleitorais, como porte populacional e grau de urbanização também devem afetar os retornos eleitorais de políticas de bens privados. Em pequenos municípios da zona rural, o formulador de políticas maximizador de votos pode contar com o auxílio de chefes políticos locais e de "cabos eleitorais" para monitorar os eleitores e garantir que estes cumpram sua parte votando no partido governista. Nestes municípios, a política é uma atividade que envolve basicamente a interação face-a-face em comunidades pequenas e relativamente homogêneas, o que tende a facilitar o controle sobre o eleitor. Nos grandes centros urbanos, em contraste, a heterogeneidade social do eleitorado é bem maior e a ação política tende a ocorrer em um contexto de relativo anonimato, fatores que atuam no sentido de elevar substancialmente os custos de monitoramento do eleitor individual (DESPOSATO, 2001; STOKES, 2005).

Para Desposatto (2001), os eleitores pobres tendem a preferir bens privados, como uma cesta básica ou um saco de cimento, ao invés de projetos de eletrificação e saneamento pelo simples de fato de que as suas carências são muito profundas e precisam ser resolvidas no curto prazo. Além de que estes eleitores têm um nível de educação e acesso à informação baixo, e por isso não têm como avaliar adequadamente os custos e benefícios de distintos tipos de política pública.

Nos estados mais ricos, em contraste, boa parte do eleitorado apresentaria preferência por bens públicos, gerando comportamentos bastante 
distintos das Assembleias Legislativas. Nestes estados, a coesão partidária (especialmente dos partidos de oposição) é maior, os partidos demonstram maior independência em relação ao Executivo, os conflitos entre Executivo e Legislativo são frequentes e a profissionalização das assembleias é maior.

\section{Uma classificação alternativa}

A tipologia de Desposatto (2001) pode levar à suposição (errônea) de que os sistemas políticos dos estados mais ricos produzem políticas públicas de caráter mais universalista, enquanto os estados mais pobres seriam predominantemente clientelistas. Isto porque toda a argumentação se baseia no pressuposto de que a preferência por bens privados irá levar à predominância de relações clientelistas. Entretanto, mesmo se aceitarmos como verdadeira esta pressuposição, não podemos inferir que a preferência por bens públicos irá garantir que a implementação das políticas governamentais seguirá critérios universalistas.

No caso dos bens públicos locais (escolas, creches, pontes, estradas, etc.), a alocação pode ser feita tanto por critérios universalistas (ex. construção de novas escolas de ensino médio em função da demanda, níveis de escolarização, etc.), como por critérios particularistas (discriminação entre municípios governados por partidos governistas ou de oposição). Como já visto neste artigo, a distribuição de bens públicos locais, segundo objetivos de maximização eleitoral, se enquadra precisamente na definição de política distributiva, constituindo uma tentativa (indireta) de trocar políticas governamentais por votos. Além disso, na medida em que a materialização de políticas nas áreas de saúde, educação, infraestrutura, etc. envolve muitas vezes a provisão de bens públicos locais em determinados municípios ou regiões, a questão dos critérios de distribuição tende a assumir peso político substancial.

Seguindo o mesmo raciocínio, devemos presumir que, ao menos hipoteticamente, políticas de bens privados podem ser guiadas tanto por 
critérios particularistas quanto universalistas. Por exemplo, políticas de transferência de renda envolvem a concessão de benefícios individualizados e excludentes (pagamento de uma remuneração em dinheiro ou em gêneros de primeira necessidade) que se aproximam da definição de bem privado. A distribuição dos benefícios pode ser feita através de redes clientelistas conectando a burocracia à esfera local, ou alternativamente, seguir critérios universalistas como o nível de renda das famílias. A partir destas reflexões, conclui-se que é necessário adicionar à dimensão da natureza dos benefícios (privados / públicos / públicos locais), a dimensão dos mecanismos de alocação (entre indivíduos / municípios / regiões) dos bens e serviços produzidos pela política.

Estabelecendo duas possibilidades quanto ao tipo de benefício produzido pela política pública (privado ou público) e outras duas quanto ao critério de alocação (político-partidário ou universalista) temos a seguinte matriz $4 \times 4$ :

\begin{tabular}{|c|c|c|}
\hline \multirow{2}{*}{$\begin{array}{c}\text { Tipo de } \\
\text { benefício }\end{array}$} & \multicolumn{2}{|c|}{ Critério de alocação } \\
\cline { 2 - 3 } & Político-partidário & Universalisa \\
\hline Privado & $\mathrm{I}$ & III \\
\hline Público & $\mathrm{II}$ & $\mathrm{IV}$ \\
\hline
\end{tabular}

No quadrante I se encaixam políticas públicas que envolvem a distribuição de bens privados como cargos públicos e cestas básicas entre eleitores, militantes e lideranças de um determinado partido ou grupo político. Este tipo de política pública irá com frequência (mas não necessariamente) redundar no estabelecimento de relações clientelistas.

No quadrante II estão classificadas as políticas públicas que permitem a distribuição de bens públicos (locais) segundo critérios particularistas. Este quadrante se encaixa na definição clássica de política distributiva. 
No quadrante III, temos uma situação em que a implementação de políticas que geram basicamente benefícios divisíveis e excludentes se dá com base em critérios universalistas. Trata-se de uma situação em que a distribuição de bens privados é focalizada em determinados grupos sociais e/ ou regiões específicas, garantindo o acesso a benefícios como transferências diretas de renda, bolsas de estudo, material de construção, cisternas, etc.

O quadrante IV abarca a distribuição de bens públicos locais segundo critérios universalistas. A provisão de bens públicos locais, nesta situação, pode servir a objetivos de caráter redistributivo. Um exemplo seria a construção de equipamentos urbanos (rede de esgoto, asfaltamento, etc.) de acordo com indicadores de vulnerabilidade social, densidade demográfica e acesso a serviços públicos, garantindo aos bairros mais pobres e populosos da cidade uma parcela maior do orçamento de investimentos da prefeitura. No quadrante IV também se encaixam políticas públicas que se aproximam à noção de bem público puro e portanto não permitem a exclusão de determinadas regiões/indivíduos do acesso. Neste último caso, o universo de beneficiários da política pública é difuso e deve necessariamente ser definido em leis e regulamentos gerais (ex. políticas ambientais, de promoção dos direitos do consumidor).

Excluindo a hipótese de provisão de bens públicos puros (que em tese não possibilitam a exclusão de beneficiários e, portanto, não são passíveis de redistribuição/focalização), podemos pensar em quatro estratégias distintas de implementação de políticas públicas, associadas às duas dimensões da tipologia. A estratégia clientelista, no quadrante I, política distributiva, no quadrante II, focalização de recursos, no quadrante III, e universalista, no quadrante IV.

\begin{tabular}{|c|c|c|}
\hline \multirow{2}{*}{$\begin{array}{c}\text { Tipo de } \\
\text { benefício }\end{array}$} & \multicolumn{2}{|c|}{ Critério de alocação } \\
\cline { 2 - 3 } & Político-partidário & Universalisa \\
\hline Privado & Clientelismo (I) & Focalização (III) \\
\hline Público & Política distributiva (II) & Universalismo (IV) \\
\hline
\end{tabular}




\section{Explicando a escolha do mix de política pública: algumas hipóteses}

Em termos um tanto esquemáticos, poderíamos concluir que a estratégia ótima do governante maximizador de votos - supondo que inexistissem constrangimentos de caráter orçamentário ou institucional - seria, em primeiro lugar, maximizar a oferta de políticas do tipo clientelista, atendendo à demanda do eleitorado pobre e, em seguida, gastar os recursos restantes ofertando políticas distributivas ${ }^{3}$. Em todos os casos, a distribuição dos recursos deveria ser pautada por critérios político-partidários, garantindo a máxima "eficiência eleitoral" dos gastos públicos. Além disso, como sugere Desposato (2001), quanto maior fosse a importância relativa do eleitorado pobre e com baixos níveis educacionais, tanto maior seria a presença de bens privados na "cesta" de políticas públicas escolhida pelo governo.

Esta formulação esquemática ignora algumas dimensões importantes na análise de políticas públicas que é preciso ressaltar. Primeiro, a argumentação de Desposato (2001) se baseia exclusivamente no comportamento dos legisladores; no entanto, sabemos que o Poder Executivo e suas burocracias, onde operam incentivos e constrangimentos distintos, têm substancial influência na formulação e implementação de políticas públicas. Um aspecto importante notado por Geddes (1994) é que os chefes do Executivo, responsáveis por liderar e coordenar as atividades da burocracia, precisam atender a coalizões eleitorais muito mais amplas e heterogêneas do que os parlamentares. Portanto, os primeiros teriam maiores incentivos

3 Adota-se aqui o pressuposto basilar da literatura da escolha racional, segundo o qual os políticos são indivíduos auto-interessados e racionais e que a formulação de políticas públicas atende aos imperativos de maximização de votos. Esta literatura também presume que os eleitores são motivados pelo autointeresse, sendo a decisão do voto afetada pelo cálculo dos custos e benefícios relativos das políticas públicas do ponto de vista do eleitor individual (AMES, 2001; CALVO; MURILLO, 2004; COX; MCCUBBINS, 1986; DAHLBERG; JOHANSSON, 2002; MAYHEW, 1974). 
para implementar políticas públicas de maior escopo, capazes de gerar benefícios coletivos e atender a grandes parcelas da população.

Um outro ponto é que Desposato se concentra quase que exclusivamente sobre as características da "demanda" por políticas públicas, esquecendo-se de investigar o papel autônomo dos atores que respondem pela "oferta" de políticas, especialmente as elites políticas e burocráticas. $\mathrm{O}$ argumento de que o ciclo político-eleitoral influencia a formulação e implementação de políticas públicas, embora intuitivamente poderoso, não é passível de aplicação a todo e qualquer tipo de política pública. Neste sentido, a literatura neo-institucionalista argumenta que os formuladores de políticas públicas não são motivados apenas pela maximização de votos, entre outras razões porque os ocupantes de cargos públicos detêm certa autonomia frente às pressões dos eleitores e grupos sociais. A existência de burocracias regidas por princípios universalistas de contratação e promoção pode garantir, em alguns setores, certo insulamento do processo decisório frente às pressões político-partidárias (EVANS, 1995; SKOCPOL, 1992). Para os neoinstitucionalistas as motivações dos atores estatais refletem, ao menos parcialmente, as posições institucionais que estes ocupam: enquanto representantes eleitos são mais sensíveis às pressões sociais e fatores eleitorais de curto prazo, o mesmo não se pode dizer de funcionários públicos e administradores de alto escalão cuja ascensão ao cargo e possibilidades de avanço na carreira independem do apoio do eleitorado.

Quanto menor o grau de institucionalização da burocracia e da política pública, e quanto maior a politização das nomeações dos cargos de alto e médio escalão, tanto mais provável será verificarmos a prevalência da lógica da maximização eleitoral, sendo o oposto verdadeiro para burocracias insuladas da competição política. Burocracias mais fortes e insuladas serão encontradas naqueles casos onde a contratação e a ascensão dos funcionários na organização se realizam com base no mérito e no tempo 
de serviço; além disso, parte significativa dos cargos do topo da hierarquia são reservados para preenchimento por funcionários de carreira, garantindo a coesão interna e a autonomia relativa do corpo burocrático. De forma análoga, quanto maior a proporção de cargos abertos à nomeação de pessoas de fora da organização, maior será a probabilidade da burocracia sofrer influências de interesses externos, por exemplo, de partidos e líderes políticos (EVANS, 1995; GEDDES, 1994; PAGE, 1992; SILBERMAN, 1993).

No caso brasileiro, a política de nomeações do alto escalão burocrático tem importância fundamental para o processo de produção de políticas públicas, em virtude da baixa institucionalização da burocracia aliada à centralidade do Poder Executivo no processo decisório governamental. Na expressão de Ben Ross Schneider (1994), no Brasil se observa um processo de "formulação não-institucionalizada" de políticas públicas. Isto porque as organizações governamentais são extremamente porosas aos interesses externos e o número de níveis hierárquicos abertos à nomeação de pessoas de fora da organização é elevado; além disso, a burocracia é altamente complexa, mas a divisão do trabalho é fluida; por fim, os métodos empregados são altamente discricionários (SCHNEIDER, 1994). Em tal contexto, a estratégia de nomeações de cargos burocráticos adotada pelo chefe do Executivo torna-se crucial para garantir (ou não) a racionalidade e a consistência interna do aparato burocrático e, assim, para o sucesso ou insucesso da agenda de políticas governamentais.

Barbara Geddes (1994), analisando os países latino-americanos, identifica um "dilema político" enfrentado por todos os presidentes da região frente a duas possíveis estratégias de utilização da burocracia: ou o preenchimento de cargos visando maximizar o apoio político e garantir maiorias estáveis, ou a busca da eficiência burocrática, garantindo-se um melhor desempenho na implementação do programa de governo no longo prazo pela escolha do alto escalão segundo competências técnicas. No caso bra- 
sileiro, o dilema identificado por Geddes (1994) seria reforçado em função da singularidade do nosso sistema político, que combina proporcionalidade, multipartidarismo, Executivos fortes e formação de coalizões amplas e heterogêneas. O alto grau de fragmentação partidária obriga os presidentes a se sustentar em coalizões multipartidárias semelhantes àquelas construídas nos sistemas parlamentaristas europeus. Portanto, de modo a garantir a disciplina partidária no legislativo, a distribuição de postos governamentais tende a seguir certa proporcionalidade entre a força dos partidos no legislativo e a sua representação no Executivo (AMORIM NETO, 2007).

Em tal contexto, uma estratégia fundamental na implementação de programas governamentais é a "compartimentalização" da burocracia (GEDDES, 1994). A compartimentalização envolve o recrutamento meritocrático, em caráter informal, para os postos diretivos de secretarias e agências públicas consideradas estratégicas para a realização de políticas prioritárias de governo. Como demonstrado por Evans (1995), Nunes (1997) e Schneider (1994), esta estratégia foi utilizada sistematicamente por presidentes desenvolvimentistas como Kubistcheck e Vargas, de modo a garantir o sucesso dos programas de estímulo à industrialização capitaneados pelo Estado. Para que a compartimentalização seja bem-sucedida, é necessário que o chefe do Executivo seja capaz de estabelecer uma "divisão de trabalho" entre secretarias e órgãos "técnicos" e "de patronagem", garantindo através destes últimos um fluxo de cargos e verbas suficiente para atender aos partidos da coalizão governista.

Diante das especificidades do sistema político brasileiro, podemos dizer que a análise das relações estratégicas entre a burocracia, os partidos políticos e o chefe do Executivo é fundamental para compreender a escolha do mix de políticas públicas implementadas pelo governo. $\mathrm{Na}$ medida em que a burocracia é um agente dotado de centralidade no processo decisório de políticas públicas, as estratégias de nomeação dos qua- 
dros burocráticos de alto escalão têm peso importante na determinação os produtos da ação governamental. Em princípio, a "partidarização" da burocracia tende a estar associada à instrumentalização político-eleitoral das agências governamentais, resultando em políticas públicas do tipo clientelista ou distributivo. Analogamente, quando o padrão de nomeação segue critérios de mérito e competência e as agências são insuladas da competição política, tanto mais provável será observarmos a produção de políticas de corte universalista (quadrantes III e IV da tipologia).

As estratégias de controle político da burocracia são, por sua vez, afetadas pela competição político-eleitoral e pela configuração do sistema partidário. Chefes do Executivo que lideram partidos pequenos e que portanto precisam do apoio de um grande número de outros partidos, devem, na maioria dos casos, ter que distribuir um maior número de cargos para garantir a governabilidade (GEDDES, 1994).Abaixo são discutidos, em maior detalhe, alguns possíveis fatores hipotéticos que permitem explicar as escolhas de política pública dos governos, a saber: competição política horizontal (entre partidos/coalizões distintas); fatores sócio-econômicos e demográficos; e competição vertical (entre esferas de governo).

\section{Competição política horizontal}

De modo geral, ambientes eleitorais mais competitivos e fragmentados deverão se caracterizar por uma maior tendência à politização da burocracia e à oferta de políticas públicas do tipo I (clientelismo). O estudo de Chibber (2004) sobre os sistemas partidários estaduais indianos demonstrou, neste sentido, que os estados com menores taxas de fragmentação partidária apresentavam maior capacidade de ofertar políticas governamentais que geram bens públicos. Seguindo uma linha de raciocínio semelhante, Mesquita et al (2001) argumentaram que em contextos nos quais a coalizão vencedora é pequena, os governantes estariam mais 
propensos a prover bens privados - como cargos e verbas - em troca de apoio político.

O grau de contestabilidade da arena eleitoral também é importante na medida em que afeta o horizonte temporal dos governantes. Um trabalho comparativo recente sobre os sistemas políticos estaduais brasileiros argumentou que, nos estados onde as eleições são relativamente menos competitivas e o partido/coalizão do governador goza de larga vantagem com respeito à oposição, o horizonte temporal do governador e seu grupo político tende a ser mais longo (ALSTON et al, 2007). Com isso, há uma maior probabilidade de o chefe do Executivo se preocupar com a implementação de programas governamentais que produzem retornos de longo prazo (bens públicos) e que por sua vez requerem estratégias de nomeação menos partidárias. De forma análoga, quando a arena eleitoral se caracteriza pela instabilidade e baixa probabilidade de reeleição/continuidade política, os governadores se veriam induzidos a perseguir estratégias de sobrevivência política de curto prazo, envolvendo a distribuição de cargos e recursos entre correligionários ou mesmo a utilização de meios ilícitos para levantar recursos para campanha e busca do enriquecimento pessoal ${ }^{4}$.

Outra variável a ser considerada, de forma independente do grau de competitividade eleitoral, é a intensidade do conflito inter-elite. Um interessante estudo comparativo sobre política industrial desde o regime militar até aos anos 1990 em dois estados brasileiros - Rio de Janeiro e Minas Gerais - demonstrou que os padrões de cooperação e competição entre as elites nos dois casos afetaram diretamente o funcionamento da burocracia e, em conseqüência, os resultados da política pública (MONTERO, 2001). No caso mineiro, verificou-se um padrão recorrente de

4 Boa parte das evidências e dos argumentos apresentados neste trabalho se refere ao processo decisório na esfera dos estados. Entretanto, parece razoável supor que argumentos similares são aplicáveis também à esfera local. 
acomodação entre as elites políticas, mesmo entre partidos adversários. Por conta do caráter "centrista" e coalescente da política mineira, foi possível o estabelecimento de um consenso mínimo entre os grupos dirigentes do estado que permitiu que a burocracia responsável por implementar as políticas de estímulo à industrialização fosse preservada da competição política $^{5}$. Já no caso do Rio de Janeiro, a presença de blocos políticos bem definidos e fortemente antagônicos, que refletia a tradição de populismo urbano do estado, solapou qualquer possibilidade de montagem de uma agenda de desenvolvimento de longo prazo. Dados os níveis elevados de conflito entre as elites cariocas e a persistente instabilidade da arena eleitoral, os governadores tinham fortes incentivos para investir em estratégias de controle partidário do aparato burocrático e criação de redes clientelistas de apoio. Como resultado, a política industrial do estado foi frequentemente negligenciada ou manipulada para atender objetivos políticos de curto prazo (MONTERO, 2001, p. 61-63).

Este estudo comparativo sugere que, em estados onde a intensidade da competição inter-elites é maior (geralmente em função de um maior grau de polarização ideológica), tanto maior será a possibilidade do conflito político-partidário se mover da arena legislativa para a burocracia, dificultando a adoção de estratégias mais universalistas de implementação de políticas públicas. Ou seja, dada a ausência de um consenso mínimo entre as elites políticas sobre as agendas de política pública, os governadores terão fortes incentivos para "partidarizar" o aparato burocrático, especialmente onde a alternância de poder entre blocos políticos antagônicos é frequente. O trabalho de Montero (2001) complementa,

5 Montero (2001) parte do pressuposto de que o longo histórico de acomodação entre as elites políticas de Minas Gerais seria consequência direta da força das oligarquias e da política clientelista no estado desde a República Velha. Entendo que esta é uma interpretação incompleta e enviesada, pois desconsidera um elemento fundamental da política mineira após o retorno a democracia nos anos 1980: o caráter consistentemente "centrípeto" da competição política, expresso na força eleitoral de dois grandes partidos de centro, o PMDB e o PSDB. 
neste sentido, o argumento de Alston et al (2007), ao sugerir que níveis elevados de polarização política devem vir associados à instabilidade na arena eleitoral, o que, por sua vez, induz os governantes a trabalhar com estratégias de maximização eleitoral de curto prazo.

Em resumo, as evidências empíricas disponíveis sugerem que estratégias de implementação de políticas públicas do tipo I (clientelismo) e II (política distributiva) serão mais comuns em sistemas políticos caracterizados por: a) um alto grau de competitividade eleitoral e fragmentação partidária;

b) um padrão mais conflituoso de competição política;

c) por um horizonte temporal mais curto do ponto de vista dos governantes, em virtude da presença das condições (a) ou (b) ou ambas.

Fatores sociais, econômicos e demográficos X competição política

A relação estabelecida entre competitividade eleitoral e as escolhas de política pública dos governos nos obriga a repensar a formulação original de Desposato (2001) a respeito do impacto do contexto socioeconômico e demográfico sobre a demanda por bens e serviços governamentais. Como já discutido acima, Desposato supõe que os estados mais pobres e menos urbanizados deveriam apresentar uma maior propensão ao clientelismo, em decorrência da propensão dos eleitores de menor renda e escolaridade a demandar bens privados. Entretanto, quando se introduz a variável "competição política" a questão ganha em complexidade, na medida em que se verifica uma relação bastante estreita entre o grau de desenvolvimento econômico e a competitividade eleitoral. Via de regra, os estados e municípios mais ricos e desenvolvidos são também aqueles onde a arena eleitoral é mais competitiva e fragmentada (BORGES, 2007; CARVALHO, 2003). Ora, as evidências empíricas de que dispomos sugerem que cenários eleitorais mais competitivos geram incentivos para a politização da burocracia e para estratégicas não-universalistas 
de implementação de políticas públicas. Portanto, não é possível concluir que as regiões mais desenvolvidas se caracterizariam pela predominância da oferta (universalista) de bens públicos.

Com isto não se pretende, no entanto, negar o argumento de que os eleitores de maior renda e escolaridade apresentam preferência por políticas do tipo bens públicos. De fato, esta argumentação é logicamente consistente, e congruente com evidências apresentadas por outros estudos (CALVO; MURILLO, 2004; GIBSON; CALVO, 2000).Dentre outros fatores relativos ao impacto do contexto social e econômico sobre o comportamento eleitoral, pode-se supor que, à medida que a renda (privada) aumenta, diminui a dependência dos eleitores frente ao governo para satisfação de suas necessidades básicas e imediatas, e com isso cresce a demanda por bens e serviços coletivos que não podem ser ofertados privadamente.

Há que se considerar, neste sentido, a existência de uma relação de causalidade múltipla envolvendo desenvolvimento econômico, competição política e oferta de políticas públicas. Se por um lado níveis mais elevados de renda e urbanização aparecem acompanhados de uma maior demanda por bens públicos, por outro é de se supor que o aumento da competição eleitoral (associada ao desenvolvimento econômico) irá tornar os eleitores mais seletivos e exigentes, ampliando os custos de "comprar" apoio político por meio da oferta de políticas públicas. Colocando em outros termos, quando diversos partidos/coalizões políticas competem entre si pelo apoio do eleitorado, a tendência é o custo de obter este apoio se ampliar. 


\section{Custo de obtenção de apoio político}

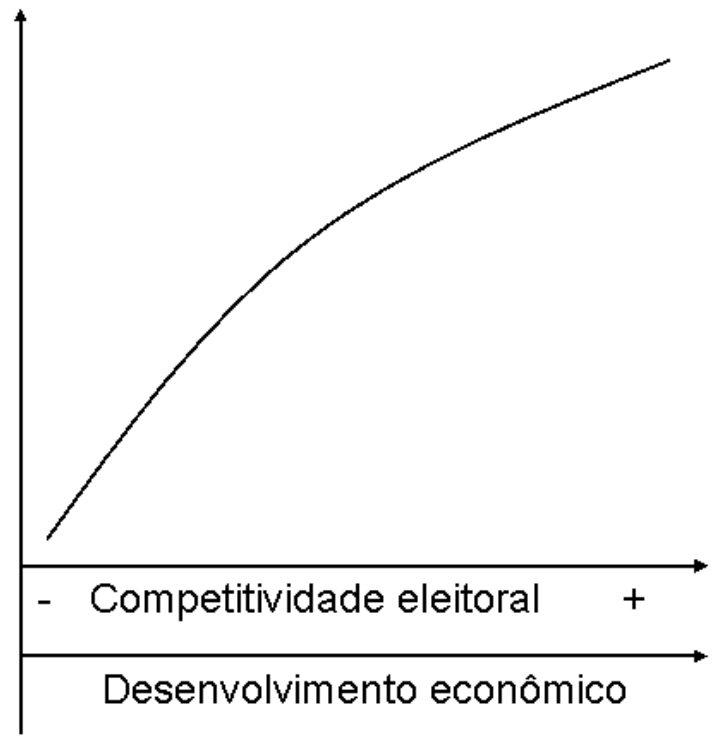

Diante do caráter competitivo e fragmentado da arena eleitoral, torna-se necessário ao governante lidar com os custos de formação de coalizões legislativas, utilizando a burocracia como moeda de troca política, e garantindo aos parceiros o controle sobre programas governamentais capazes de maximizar apoio eleitoral. Hipoteticamente, quanto maior for o grau de competitividade, fragmentação e polarização da arena eleitoral, tanto maior será o tamanho relativo da "cesta" de políticas distributivas e clientelistas necessárias à "compra" de apoio político pelos governantes. Sabemos, por outro lado, que os retornos eleitorais potenciais da oferta discricionária de bens privados pelos governantes tendem a decair com o aumento da renda e da escolaridade. Assim, em regiões mais urbanizadas e desenvolvidas, com níveis mais elevados de renda e escolaridade, deveremos observar um maior peso dos bens públicos no "cesta" global de políticas públicas. 
O aumento da demanda por bens públicos deve dificultar a obtenção de apoio político, uma vez que são menores as possibilidades de garantir o apoio do eleitorado em troca dos benefícios concedidos. Como já visto, na hipótese da distribuição estratégica de bens públicos locais não está presente uma conexão direta entre o recebimento de um dado benefício pelo eleitor e uma recompensa dada ao governo na forma de um voto de apoio.

Resumindo o que foi dito nos parágrafos anteriores, podemos inferir que, ceteris paribus, o custo de obtenção de apoio político tende a ser mais elevado nas regiões mais ricas e desenvolvidas, dada a associação entre desenvolvimento econômico e competitividade eleitoral ${ }^{6}$. Na medida em que, no caso brasileiro, a burocracia pública apresenta baixo grau de institucionalização, a capacidade de resistência das agências burocráticas às pressões de partidos políticos e grupos de interesse e, portanto, a capacidade de implementação de políticas universalistas, irá depender da força política do núcleo do governo. Com isso, governos que atuam em ambientes eleitorais mais competitivos, e que enfrentam maiores custos de formação de coalizões, terão maiores dificuldades de garantir o insulamento de setores estratégicos da burocracia com vistas à implementação de políticas públicas capazes de produzir externalidades positivas e de longo prazo. Ou seja, os custos de compartimentalização da burocracia, com a definição de setores de ação governamental estratégicos tendem a ser elevados. Estas dificuldades serão tanto maiores quanto maior for a intensidade do conflito entre os blocos políticos competidores.

Assim, em contextos de alta competitividade e polarização política, mais comuns em regiões mais urbanizadas e desenvolvidas, é maior o risco de formação de uma dinâmica predatória, na qual governantes an-

6 Esta é, obviamente, uma relação probabilística, uma vez que não há uma associação mecânica e direta entre desenvolvimento e grau de competitividade, além de que fatores como os padrões historicamente construídos de cooperação e conflito entre as elites também devem afetar os custos de obtenção de apoio político e montagem de coalizões. 
siosos por fortalecer suas frágeis bases de apoio irão cultivar e alimentar coalizões amplas e heterogêneas através da distribuição discricionária de cargos e verbas. Por outro lado, a elevação constante dos custos de mobilização do eleitorado deve induzir os políticos - tanto governistas quanto de oposição - a se engajarem em uma competição desenfreada pela obtenção de benefícios divisíveis, que serão utilizados para cultivar e manter nichos eleitorais necessários a sua sobrevivência política.

Os resultados esperados do aprofundamento dessa dinâmica no longo prazo são o desmantelamento dos núcleos de excelência da administração pública, em virtude da politização extremada e alta rotatividade de pessoal, e falta de continuidade das ações governamentais. Também devem ser observados déficits públicos elevados em virtude dos altos custos de formação e manutenção de coalizões e perda da capacidade de controle e regulação do aparato administrativo estatal, favorecendo a emergência de "anéis de corrupção"

Com base nesta formulação, pretende-se argumentar que o problema crucial a ser enfrentado pelos estados de alta competitividade eleitoral diz respeito à institucionalização da competição política e regulação do conflito entre as elites. Na ausência de espaços mínimos de consenso e de incentivos à cooperação entre as forças políticas adversárias, são maiores as probabilidades do conflito político se deslocar do legislativo e do sistema partidário para a burocracia, redundando em uma dinâmica política predatória. Como já argumentado anteriormente neste trabalho, o melhor desempenho do estado de Minas Gerais relativamente ao Rio de Janeiro, na implementação de políticas de fomento à indústria encontra-

\footnotetext{
7 Ainda que hipotética, a dinâmica aqui descrita poderia ser aplicada, com poucas alterações, ao caso do Rio de Janeiro. Do ponto de vista dos indicadores de competitividade eleitoral e polarização política, o estado desponta claramente no cenário nacional (ver BORGES, 2007). Por outro lado, é também patente a falência dos órgãos governamentais e serviços públicos, e a proliferação de espaços tomados pelo crime e por máfias de toda ordem.
} 
ria explicação precisamente no caráter menos conflituoso e mais centrista da competição política no primeiro estado.

No caso dos estados menos desenvolvidos, onde via de regra são menores os níveis de competitividade eleitoral, há que se considerar duas ordens de fatores para entender as escolhas de política pública. De um lado, por conta do maior peso da administração pública na economia e da maior dependência da sociedade vis-à-vis o governo, estão presentes oportunidades estruturais para estratégias de extração de rendas (rent-seeking) da parte dos governantes. Em tal contexto, o governismo endêmico dos partidos políticos e as largas possibilidades de compra de apoio por meio da oferta de bens privados facultam às elites políticas construir e consolidar organizações políticas voltadas para o controle patrimonial das instituições estatais, garantindo a extração de rendas públicas e privadas para a manutenção das mesmas organizações e do poder dos grupos dominantes. Por outro lado, os governantes dos estados pobres enfrentam menores custos de obtenção de apoio político, em virtude dos maiores retornos eleitorais da oferta de bens privados. Além disso, a arena eleitoral tende a ser menos competitiva e fragmentada, o que também contribui para reduzir os custos de formação de coalizões. Ao menos hipoteticamente, portanto, nestes contextos seria possível montar coalizões legislativas e eleitorais de baixo custo, capazes de sustentar politicamente estratégias bem sucedidas de compartimentalização burocrática para a implementação de políticas públicas universalistas.

Em muitos casos, no entanto, predominam nos estados mais pobres estratégias predatórias de extração e distribuição de rendas. Isto porque a competição entre as elites políticas nestas regiões é, também e principalmente, uma competição pelo controle de empreendimentos patrimoniais, os quais, por sua vez, respondem por parcela significativa do PIB estadual. Nos estados mais atrasados, a administração pública tem peso muito grande na economia. Além disso, não é incomum se observar uma grande 
sobreposição entre o poder político e o econômico, uma vez que os grupos privados são, com frequência, liderados por clãs familiares com larga tradição na política. Na medida em que a atividade política é em si mesma uma importante - senão a mais importante - estrada para a ascensão social, a competição político-eleitoral irá se tornar, não raro, uma disputa entre facções e clãs político-familiares desejosos de aumentar a sua parcela das riquezas produzidas pelo estado, seja com vistas ao enriquecimento próprio, seja com o objetivo de alimentar as suas máquinas políticas (ex. garantindo recursos para financiamento de campanhas eleitorais).

Nestes contextos, é possível identificar um dilema da ação coletiva, uma vez que às elites governantes, coletivamente, interessaria implementar políticas públicas capazes de promover o desenvolvimento econômico e social do estado, e assim ampliar a capacidade de extração de receitas do governo. Não se pode esquecer ainda que os efeitos positivos do crescimento econômico de longo prazo sobre a renda dos eleitores tendem a se traduzir em maiores níveis de apoio político, passíveis de apropriação por toda a coalizão governista. Por outro lado, para garantir a produção deste bem público através do fortalecimento institucional da burocracia e criação de espaços universalistas, os membros da coalizão tomados individualmente necessitariam abrir mão do seu quinhão de benefícios divisíveis - ex. cargos de livre nomeação - necessários a sua sobrevivência política no curto prazo.

No longo prazo, a solução deste dilema passaria pela criação de organizações políticas capazes de disciplinar a competição entre as elites e a distribuição de benefícios particularistas entre os membros da coalizão de governo. Assim, em contextos caracterizados pela presença de uma organização dominante, capaz de determinar de forma hierárquica e centralizada a parcela "justa" das benesses governamentais devida a cada um dos membros da organização, haveria maiores possibilidades para a compartimentalização da burocracia com vistas à promoção do desen- 
volvimento econômico e social do estado. Analogamente, em contextos marcados pela fragmentação das elites governantes e pela disputa entre facções oligárquicas de poderio mais ou menos equivalente, as dificuldades de superação do dilema da ação coletiva tenderiam a serem maiores.

As evidências de que dispomos indicam, de fato, que alguns casos bem-sucedidos de compartimentalização da burocracia nas regiões mais pobres do país se caracterizam pela presença de máquinas políticas dominantes, capazes de "racionalizar" a distribuição de recursos de patronagem e a competição por rendas derivadas de empreendimentos patrimoniais. Como observado por Bonfim (1999) e Borges (2000), os estados da Bahia e do Ceará se destacaram nos anos 1990 pela implementação de programas de ajuste fiscal e reforma do Estado, os quais viabilizaram a tomada de empréstimos de longo prazo para realização de investimentos em infraestrutura e a adoção de estratégias agressivas de atração de investimentos privados. Em ambos os casos, o ajuste fiscal foi implementado a partir do insulamento e modernização institucional das Secretarias da Fazenda.

No caso da Bahia, uma coalizão dominante formada ainda no regime militar pelas forças da Arena, e posteriormente pelo Partido da Frente Liberal (PFL) e outros partidos "satélites" em torno da liderança carismática e autocrática do ex-governador Antônio Carlos Magalhães garantiu ao poder executivo estadual os recursos políticos necessários à estratégia de insulamento da burocracia setorial. No caso do Ceará, o ajuste fiscal foi viabilizado pela ascensão ao poder de lideranças destacadas da burguesia industrial do estado que se mostraram bem sucedidas na criação de uma máquina política modernizadora, organizada no interior da seção estadual do PSDB. Os chamados "jovens empresários" foram capazes de por fim ao domínio de três famílias políticas que por décadas haviam submetido o estado a uma competição predatória por rendas patrimoniais e recursos de patronagem, instaurando um regime de partido dominante. 
Uma dinâmica bastante distinta se desenrolou no caso do Piauí, estado caracterizado pela fragmentação e fragilidade das elites políticas. A debilidade das organizações políticas estaduais abriu espaço para um padrão competitivo predatório, que envolvia a disputa entre facções rivais pela extração de rendas públicas e privadas no menor espaço de tempo possível. Tal dinâmica teve como subprodutos o enfraquecimento do núcleo técnico da burocracia, irresponsabilidade fiscal, ausência de políticas consistentes de promoção do desenvolvimento e relativa estagnação econômica (BONFIM, 2004).

Estas evidências, ainda que esparsas, sugerem que a presença de organizações políticas capazes de disciplinar a competição pelo controle e montagem de empreendimentos patrimoniais nos estados mais atrasados é fundamental para garantir o insulamento de setores estratégicos do aparato administrativo. O processo de racionalização da máquina pública, por sua vez, tende a favorecer a implementação de políticas públicas capazes de alavancar o desempenho da economia ${ }^{8}$.

\section{Competição vertical}

Em democracias federais como a brasileira, não só verificamos processos de competição horizontal (diferentes partidos e candidatos disputando o voto dos eleitores) como também de competição vertical (distintas esferas de governo competindo por um mesmo "pool" de eleitores através de políticas públicas semelhantes). Isto é, ao buscar o apoio do

8 Por outro lado, não se pode esquecer que a compartimentalização da burocracia tem um custo social e político significativo. Pois ao mesmo tempo em que se privilegiam determinados setores do aparato administrativo, com medidas como recrutamento meritocrático e investimentos em treinamento e modernização institucional, há o risco dos governantes tentarem compensar a perda de espaços para a barganha política com a "superpolitização" de outras burocracias setoriais. Usualmente, as agências da área social (saúde, educação) costumam ser as mais atingidas por este trade-off perverso entre meritocracia e política de patronagem. 
eleitorado por meio de políticas públicas, os governos de nível mais baixo (locais ou estaduais) competem com políticas similares ofertadas pelos governos de nível mais alto (federal ou estadual) (MIGUÉ, 1997).

A competição vertical afeta as escolhas de política pública dos governos na medida em que tende a aumentar os custos de mobilização do eleitorado. Em especial, políticas governamentais do tipo I, de caráter clientelista, serão menos eficazes na geração de retornos eleitorais quando sujeitas à competição de políticas semelhantes ofertadas por um nível superior de governo. Isto porque as relações clientelistas tendem a ser mais estáveis quando os clientes não têm outra alternativa exceto recorrer ao partido/ coalizão de governo para obter acesso a determinados bens e serviços.

Hipoteticamente, a competição vertical entre partidos adversários ocupando níveis distintos de governo deve criar incentivos para a substituição de políticas clientelistas por políticas universalistas. Ou seja, devemos observar um movimento do quadrante I (bens privados, clientelismo) ao quadrante III (alocação universalista de bens privados) na tipologia.

Embora Desposato (2001) presuma que os mais pobres têm preferência por políticas do tipo bens privados, que redundam em relações clientelistas (I), ainda assim é preciso perguntar se estes eleitores não estariam meIhor no quadrante (III), em que o acesso aos bens privados seria garantido por regras universalistas. Se parece lícito supor que os eleitores pobres priorizam bens privados capazes de suprir necessidades básicas e imediatas, também parece razoável presumir que, em razão da sua situação de carência extrema, os mais pobres valorizam fortemente a segurança econômica.

Deste ponto de vista, eleitores racionais devem preferir políticas do tipo III ao tipo I. Isto porque no quadrante III a incerteza com respeito ao recebimento do benefício deve ser menor. Na situação I, o eleitor depende de intermediários (ex. prefeitos e lideranças locais) cujo status futuro é incerto, diante da possibilidade de uma mudança nas urnas. Na situação 
III, a provisão do benefício é menos incerta, pois está garantida por regras geralmente estabelecidas em lei. Sendo assim, podemos concluir que políticas do tipo III garantem maior segurança econômica relativamente a políticas do tipo I.

Da perspectiva do partido/coalizão que ocupa um nível governo superior (inferior) e deseja roubar votos de partidos de oposição que controlam esferas inferiores (superiores) de governo, a produção de políticas do tipo III, envolvendo a focalização de recursos nos mais pobres, é uma estratégia eficiente por duas razões. Primeiro porque os retornos eleitorais de políticas públicas desta natureza são mais garantidos do que de políticas de bens públicos; isto é, as políticas públicas que focalizam os mais pobres apresentam maior "eficiência eleitoral". Por outro lado, partindo do pressuposto de racionalidade do eleitor, políticas do tipo III serão mais efetivas em roubar votos do que do tipo I. Por fim, e não menos importante, o partido/ coalizão que deseja crescer junto ao eleitorado da oposição não possui incentivo para restringir a distribuição de recursos aos redutos governistas, adotando critérios político-partidários de caráter mais estreito ${ }^{9}$.

A expansão das políticas de transferência de renda do governo federal no primeiro mandato do presidente Lula é um exemplo claro da dinâmica descrita acima. Como já notado por autores como Hunter e Power (2007) e Zucco (2008) o crescimento da votação do PT nas regiões mais pobres do país na eleição de 2006 esteve fortemente associado aos programas sociais do governo federal, notadamente o Bolsa Família. Este último programa, que envolve a transferência condicional de renda a famílias que se encontram abaixo da linha oficial de pobreza, se enquadra na definição de políticas públicas de tipo III: trata-se de um programa

9 Pois se o objetivo é manter a votação das eleições anteriores e tirar votos da oposição, a estratégia mais lógica é atender tanto redutos governistas quanto oposicionistas. Assim, a utilização de critérios universalistas de alocação pode, muito bem, se constituir em estratégia ótima do ponto de vista eleitoral. 
que provê um benefício individual a partir de critérios universalistas. As evidências demonstram que, embora não determinante, o Bolsa-Família seria um dos fatores responsáveis pela mudança nos padrões territoriais de votação do PT nas eleições presidenciais de 2006, com forte crescimento do partido nas regiões Norte e Nordeste ${ }^{10}$.

Outras pesquisas demonstraram ainda que parte dos retornos eleitorais do carro-chefe das políticas federais de transferência de renda foi revertida para campanhas estaduais do PT e seus aliados, em estados previamente dominados por partidos de centro e direita adversários do PT na esfera nacional. Utilizando análises de correlação simples, Borges (2007) encontrou associações estatísticas significativas entre a cobertura do Bolsa Família nos estados e a votação obtida pelo PT, bem como pelo conjunto dos partidos de esquerda, nas eleições estaduais proporcionais e majoritárias. O mesmo trabalho demonstrou que o crescimento do PT e demais partidos de esquerda se deu basicamente nos estados mais pobres, com menores taxas de urbanização, onde as forças de centro-direita haviam sido, até então, predominantes. Estes estados também se caracterizavam pelo alto grau de controle sobre a arena eleitoral exercido pelas elites estaduais, tendo em vista a hegemonia de umas poucas famílias políticas e partidos nas eleições majoritárias e proporcionais.

Podemos concluir, assim, que o processo de competição vertical entre o governo nacional do PT e os governos estaduais teve como um dos seus desdobramentos a rápida expansão de um programa focalizado de transferência de renda, o qual contribuiu para enfraquecer as redes clientelistas controladas pelas máquinas políticas estaduais. Esta política pública gerou retornos eleitorais significativos para o partido do presidente e

10 Não se quer argumentar aqui que a criação e expansão do Bolsa Família foram condicionados tão somente por fatores de cálculo eleitoral; no entanto, não há como negar o relevante papel destes aspectos sobretudo no que diz respeito ao timing e magnitude da expansão do programa no primeiro mandato do presidente Lula. 
seus aliados nas eleições estaduais, enfraquecendo as redes clientelistas controladas pelos governos dos estados.

\section{Conclusão}

A democracia brasileira vem se caracterizando pela combinação entre um sistema presidencialista com Executivos fortes, um sistema multipartidário de partidos fracos, e um federalismo descentralizado que concede papel significativo aos atores e instituições subnacionais na formulação e implementação de políticas públicas. O mix institucional brasileiro se caracteriza ainda pela baixa institucionalização e porosidade das burocracias públicas aos interesses externos. A centralidade das burocracias do Poder Executivo no processo decisório governamental, de um lado, e do outro, os imperativos da governabilidade, que obrigam os governantes a trocar apoio político por cargos, resultam em um modelo de formulação de políticas públicas não-institucionalizado, no qual as estratégias de nomeação do alto escalão burocrático adquirem papel crucial.

Partindo desta visão sobre as instituições democráticas brasileiras, o trabalho argumentou, amparado em evidências de algumas pesquisas sobre o tema, que ambientes eleitorais mais competitivos e fragmentados deverão se caracterizar por uma maior tendência à politização da burocracia e à oferta de políticas públicas não-universalistas. Por outro lado, argumentou-se que regiões com maiores índices de desenvolvimento econômico (as quais, via de regra, também apresentam níveis mais elevados de competitividade eleitoral) serão marcadas por maiores custos de formação de coalizões eleitorais e legislativas e uma demanda mais elevada por bens públicos locais. De forma análoga, regiões menos desenvolvidas e de menor competitividade eleitoral se caracterizariam pelos retornos eleitorais mais elevados da distribuição discricionária de bens 
privados (clientelismo) e por menores custos de formação de coalizões eleitorais e legislativas. Em ambos os casos, o sucesso de estratégias de compartimentalização da burocracia para produção de políticas públicas universalistas dependeria da natureza dos padrões de cooperação/competição entre as elites políticas.

Nos estados mais pobres e de menor competitividade, o insulamento burocrático teria maior probabilidade de sucesso quando da presença de uma organização política dominante, capaz de "racionalizar" a política de patronagem. Já em contextos de maior desenvolvimento socioeconômico e competitividade eleitoral, onde são maiores os custos de mobilização de apoio político, sistemas caracterizados por padrões de comportamento coalescente das elites, e por um maior grau de consenso entre as forças políticas têm maiores possibilidades de criação de espaços burocráticos preservados da competição política, permitindo a implementação de políticas públicas de longo prazo. Analogamente, padrões de competição mais conflituosos reduzem as possibilidades de formação de agendas mínimas de política pública, além de criar incentivos para a politização da burocracia.

O trabalho argumentou ainda que a competição vertical entre esferas de governo na oferta de políticas públicas semelhantes tende a reduzir os retornos eleitorais de políticas clientelistas. Além disso, sob certas condições, a competição vertical entre coalizões políticas adversárias pode criar incentivos para a oferta de políticas universalistas.

Uma das contribuições do trabalho é mostrar os limites das visões convencionais no que diz respeito ao impacto do mix institucional brasileiro sobre a produção de políticas públicas. Parte da literatura presume que, sob condições normais, as instituições políticas brasileiras - especialmente o sistema presidencialista e o sistema eleitoral proporcional - deverão produzir políticas governamentais ineficientes e de baixo impacto 
redistributivo, em virtude da fragmentação institucional e presença de fortes incentivos para o clientelismo político (AMES, 2001; MAINWARING, 1999; WEYLAND, 1996). Em particular, a literatura sobre federalismo parte do suposto de que a política estadual é dominada por lógicas patrimonialistas e não-republicanas e que estas, por sua vez, contaminam de modo irreversível o processo de formação e implementação de políticas públicas. Na definição de Hagopian (1996), se é verdade que o sistema político brasileiro, de modo geral, se caracteriza pela presença de Executivos fortes, partidos fracos e clientelismo "penetrante" (pervasive clientelism), estes traços seriam ainda mais proeminentes nas esferas estadual e local. Da mesma forma, os argumentos em torno do caráter "ultra-presidencialista" da política estadual também enfatizam a conexão entre a centralidade política do Executivo e do governador, a tibieza dos partidos e a configuração de um sistema de tomada de decisões calcado na troca de recursos de patronagem por apoio político (ABRUCIO, 1998)

As hipóteses do presente trabalho sugerem um quadro bem mais complexo e multifacetado, em que fatores socioeconômicos e demográficos, e padrões de competição política interagem para produzir variados tipos de política pública. Neste sentido, a tipologia aqui apresentada permite resgatar os ensinamentos de Edson Nunes com respeito à coexistência de diversas "gramáticas políticas" no interior das instituições políticas brasileiras, como o clientelismo, o universalismo e insulamento burocrático. Caberia assim abandonar as visões dualistas que enxergam o mundo político em preto-e-branco, como um embate entre a virtuosidade do universalismo e dos bens públicos, e os vícios do clientelismo e da distribuição de benefícios divisíveis e individualizados. Pois como sugere a argumentação desenvolvida ao longo deste artigo, a distribuição de bens privados - seja a partir de critérios universalistas ou político-partidários - pode muitas vezes se constituir em fundamento da construção de co- 
alizões políticas capazes de sustentar a produção de políticas públicas associadas a benefícios coletivos e de longo prazo.

\title{
Federalism, electoral dynamics and public policies in Brazil: a typology and some hypotheses
}

\begin{abstract}
This paper proposes a typological model to provide further understanding of the connection between public policies and electoral dynamics in a federal democracy in which the power to formulate and implement public policies is relatively decentralized. More generally, this typology of public policies is intended to move beyond the traditional dichotomies of political science - clientelism vs. universalism / catch-all parties vs. programmatic parties - offering a new analytical perspective, with a non-dualistic approach. The typology classifies public policies according to two dimensions: the criteria for allocation of resources (partisan or universal) and the nature of the goods and services produced (private or public). From the intersection of the two dimensions, the paper defines four types of strategies for the implementation of public policies: clientelism, distributive policy, policy targeting and universalism. It also proposes some hypotheses to explain the choices of public policy made by the state governments. The article takes into account three types of explanatory factors: horizontal political competition (between political parties), vertical competition (between the spheres of government), and the socio-economic and demographic context.
\end{abstract}

Keywords: Public policies. Clientelism. Electoral competition. Federalism. State government.

\section{Referências}

ABRUCIO, F. L. Os Barões da Federação: os governadores e a redemocratização brasileira. São Paulo: Hucitec, 1998.

ALSTON, L. et al. The choices governors make: political institutions and policymaking processes in the Brazilian states. Annual Conference of the International Society for New Institutional Economics, 2007. Washington, St Louis (USA), 2007. 
AMES, B. The Deadlock of Democracy in Brazil. Michigan: The University of Michigan Press: Ann Harbor, 2001.

. Political survival: politicians and public policy in Latin America. Berkeley: University of California Press, 1987.

AMORIM NETO, O. O Poder Executivo, centro de gravidade do Sistema Político Brasileiro. In: AVELAR, L.; Cintra, A.O. (Eds.) O Sistema Político Brasileiro. São Paulo: Editora Unesp; Fundação Konrad-Adenauer, 2007.

ARRETCHE, M. Estado Federativo e Política Social. Rio de Janeiro: Revan, 2000. BONFIM, W. L. S. Mudança Social no Piauí. Rio de Janeiro: Revan, 2004.

. Qual Mudança? Os Empresários e a Americanização do Ceará. Tese de doutorado. Rio de Janeiro, Rio de Janeiro: IUPERJ, 1999.

BORGES, A. Rethinking State Politics: The Withering of State Dominant Machines. Brazilian Political Science Review, n. 2, 2007.

. A Retórica da eficiência: as políticas do ajuste fiscal na Bahia. Dissertação de mestrado. Salvador, Ba: UFBA, 2000.

CALVO, E.; MURILLO, M. V. Who Delivers? Partisan Clients in the Argentine Electoral Market. American Journal of Political Science, v. 48, n. 4, 2004, p. 742757.

CARVALHO, N. R. D. E no Início eram as Bases: geografia política do voto e comportamento legislativo no Brasil. Rio de Janeiro: Revan, 2003.

CHIBBER, P.; NOORUDDIN, I. Do party systems count? The number of parties and government performance in the Indian states. Comparative Political Studies, v. 37, n. 2, 2004, p. 152-187.

COX, G.; MCCUBBINS, M. Electoral Politics as a Redistributive Game. Journal of Politics, n. 48, 1986, p. 370-389.

DAHLBERG, M.; JOHANSSON, E. On the Vote-Purchasing Behaviour of Incumbent Governments. American Political Scicence Review, v. 96, n. 1, 2002, p. 27-40.

DESPOSATO, S. Institutional Theories, Societal Realities and Party Politics in Brazil. Tese de Doutorado: University of California, Los Angeles, 2001.

DIAZ-CAYEROS, A. et al. Tragic Brilliance: Equilibrium Hegemony and Democratization in Mexico, 2003. Disponível em http://www.stanford.edu/ albertod/ tragicbrilliance.pdf.

DINIZ, E. Voto e Máquina Política: Patronagem e Clientelismo no Rio de Janeiro. Rio de Janeiro: Paz e Terra, 1982. 
EVANS, P. B. Embedded autonomy: states and industrial transformation. Princeton: Princeton University Press, 1995.

GEDDES, B. Politician's dilemma: building state capacity in Latin America. Berkeley: University of California Press, 1994.

GIBSON, E.; CALVO, E. Federalism and Low-Maintenance Constituencies: Territorial Dimensions of Economic Reform in Argentina. Studies in Comparative International Development, v. 35, n. 3, 2000, p. 32-55.

HAGOPIAN, F. Traditional Politics and Regime Change in Brazil. Cambridge: Cambridge University Press, 1996.

HUNTER, W.; POWER, T. J. Rewarding Lula: Executive Power, Social Policy, and the Brazilian Elections of 2006. Latin American Politics \& Society, v. 49, n. 1, 2007, p. 1-30.

LIMONGI, F. O Novo Institucionalismo e os Estudos Legislativos: a literatura norteamericana recente. BIB, v. 37, n. 1, 1994, p. 3-38.

MAINWARING, S. Presidentialism in Brazil: the impact of strong constitutional powers, weak partisan powers, and robust federalism. In: MAINWARING, S.; SHUGART, M.S. (Eds.) Presidentialism and democracy in Latin America. Cambridge: Cambridge University Press, 1997.

. Rethinking party systems in the third wave of democratization: the case of Brazil. Stanford, California: Stanford University Press, 1999.

MAYHEW, D. R. Congress: the electoral connection. New Haven: Yale University Press, 1974.

MESQUITA, B. B. et al. Political competition and economic growth. Journal of Democracy, v. 12, n. 1, 2001, p. 58-72.

MIGUÉ, J. L. Public Choice in a Federal System. Public Choice, n. 90, 1997, p. 230-254.

MONTERO, A. P. Making and remaking "good government" in Brazil: Subnational industrial policy in Minas Gerais. Lat Am Polit Soc, v. 43, n. 2, 2001, p. 49-80.

PAGE, E. Political authority and bureaucratic power: a comparative analysis. 2nd ed. New York: Harvester Wheatsheaf, 1992.

PEREIRA, C.; RENNÓ, L. O que é que o reeleito tem? Dinâmicas político-institucionais locais e nacionais nas eleições de 1998 para a Câmara dos Deputados. Dados, v. 44, n. 2, 2001, p. 323-362.

SCHNEIDER, B. Burocracia Pública e Política Industrial no Brasil. São Paulo: Editora Sumaré, 1994. 
SILBERMAN, B. S. Cages of reason: the rise of the rational state in France, Japan, the United States, and Great Britain. Chicago: University of Chicago Press, 1993.

SKOCPOL, T. Protecting soldiers and mothers: the political origins of social policy in the United States. Cambridge, Massachusetts; London: Belknap Press of Harvard University Press, 1992.

SOUZA, C. M. D. Constitutional engineering in Brazil: the politics of federalism and decentralization. Basingstoke: Macmillan, 1997.

STOKES, S. C. Perverse Accountability: a formal model of machine politics with evidence from Argentina. American Political Scicence Review, v. 99, n. 3, 2005, p. 315-325.

STOKES, S. C.; MEDINA, L. F. Clientelism as Political Monopoly. In: Chicago Centre on Democracy, Working Paper n. 25. Chicago, IL, 2002.

WEYLAND, K. Democracy Without Equity: Failures of Reform in Brazil. Pittsburgh: University of Pittsburgh Press., 1996.

ZUCCO, C. The President's 'New' Constituency: Lula and the Pragmatic Vote in Brazil's 2006 presidential elections. Journal of Latin American Studies, v. 40, 2008, p. 29-49.

Recebido: 16/03/2010

Aceite final: 13/04/2010 